\title{
Thermal equilibrium responses in Guzerat cattle raised under tropical conditions
}

\author{
Leandro Zuccherato Camerro ${ }^{a}$, Alex Sandro Campos Maia ${ }^{\mathrm{a}, *}$, Marcos Chiquitelli Neto ${ }^{\mathrm{b}}$, \\ Cintia Carol de Melo Costa ${ }^{a}$, Patric André Castro ${ }^{a}$ \\ a Laboratory of Animal Biometeorology, Animal Science Department, Sao Paulo State University, Jaboticabal Campus, Access Avenue Professor Paulo Donato \\ Castellane, zip code 14884-900 Jaboticabal, SP, Brazil \\ ${ }^{\mathrm{b}}$ Biology and Animal Science Department, Sao Paulo State University, Ilha Solteira Campus, Monções Street, zip code 15385-000 Ilha Solteira, SP, Brazil
}

\section{A R T I C L E I N F O}

Article history:

Received 18 December 2015

Accepted 6 July 2016

Available online 7 July 2016

Keywords:

Indirect calorimetry

Thermal equilibrium

Thermoregulation

\begin{abstract}
A B S T R A C T
The literature is very sparse regarding research on the thermal equilibrium in Guzerat cattle (Bos indicus) under field conditions. Some factors can modify the physiological response of Guzerat cattle, such as the reactivity of these animals to handling. Thus, the development of a methodology to condition and select Guzerat cattle to acclimate them to the routine collection of data without altering their physiological response was the objective of the preliminary experiment. Furthermore, the animals selected were used in the main experiment to determine their thermal equilibrium according to the thermal environment. For this proposal, the metabolic heat production and heat exchange between the animal and the environment were measured simultaneously in the field with an indirect calorimetry system coupled to a facial mask. The results of the preliminary experiment showed that the respiratory rate could demonstrate that conditioning efficiently reduced the reactivity of the animals to experimental handling. Furthermore, the respiratory rate can be used to select animals with less reactivity. The results of the main experiment demonstrate that the skin, hair-coat surface and expired air temperature depend on the air temperature, whereas the rectal temperature depends on the time of day; consequently, the sensible heat flow was substantially reduced from 70 to $20 \mathrm{~W} \mathrm{~m}^{-2}$ when the air temperature increased from 24 to $34{ }^{\circ} \mathrm{C}$. However, the respiratory latent heat flow increased from 10 to $15 \mathrm{~W} \mathrm{~m}^{-2}$ with the same temperature increase. Furthermore, the metabolic heat production remained stable, independent of the variation of the air temperature; however, it was higher in males than in females (by approximately $25 \%$ ). This fact can be explained by the variation of the ventilation rate, which had a mean value of 1.6 and $2.2 \mathrm{~L} \mathrm{~s}^{-1}$ for females and males, respectively.
\end{abstract}

(c) 2016 Elsevier Ltd. All rights reserved.

\section{Introduction}

Most of the world's cattle population is concentrated in tropical and subtropical regions (Brito et al., 2004). The Brazilian herd alone has an estimated 208 million heads (USDA, 2014), and among these, $80 \%$ are Zebu breeds (Bos indicus) and crossbred animals. Compared to other breeds, Zebu cattle have low nutritional demands and high resistance to ecto- and endoparasites (Brito et al., 2004). Moreover, these animals have increased tolerance to high temperatures and intense solar radiation (da Silva and Maia, 2013). Thus, under tropical conditions, Bos indicus animals usually perform better than Bos taurus animals, in part because of

\footnotetext{
* Corresponding author.

E-mail addresses: leandrozc@yahoo.com.br (L.Z. Camerro), alex.maia@fcav.unesp.br (A.S.C. Maia), manera@bio.feis.unesp.br (M.C. Neto), cintiacarolmc@yahoo.com.br (C.C.d.M. Costa), patric.castro@ymail.com (P.A. Castro).
}

their ability to maintain thermal balance and exchange heat with the environment.

The literature is very sparse regarding research on the thermal equilibrium in Bos indicus under field conditions, especially for Guzerat cattle. One reason for the lack of studies might be the reactivity of these animals to handling, which modifies their physiological responses, or the complexity of studies, which use indirect calorimetry outdoors. Consequently, the thermal equilibrium of beef cattle has been studied under controlled environments in climate chambers (McDowell, et al., 1953; Piccione et al., 2005; Gebremedhin et al., 2010). For example, Brown-Brandl et al. (2003), working with crossbred cattle ( $1 / 4$ Angus, 1/4 Hereford, 1/4 Pinzgauer, and $1 / 4$ Red Poll) in climate chambers, observed that an increase in air temperature from 17.5 to $34^{\circ} \mathrm{C}$ induced an increase in the respiratory rate (from 55 to 103 breathes $\mathrm{min}^{-1}$ ) and rectal temperature (from 38.9 to $40.1^{\circ} \mathrm{C}$ ), a reduction in food intake and decreased metabolic heat production.

These artificial conditions hardly resemble those that animals 
endure in the field where the air temperature, humidity, wind speed, and solar radiation vary continuously over time, which induces constant changes in their thermal balance (McArthur, 1987). Thus, developing a methodology to simultaneously study the thermal equilibrium in Guzerat cattle under field conditions with variable meteorological elements was the objective of this work.

\section{Materials and methods}

The present study was conducted at the São Paulo State University, Campus of Ilha Solteira, Brazil (latitude $20^{\circ} 25^{\prime} \mathrm{S}$ ). Seven male and nine female purebred Guzerat animals were grown in a confined system from 10 months of age until 20 months of age. For the collections, a series of adaptation and management processes were performed, starting with the dehorning of the animals soon after birth (between February and April 2013). In January 2014, the process of taming of the animals began, and in March 2014, conditioning to the use of facial masks was introduced. First, the animals were conditioned without valves and for only a few minutes. Then, the time of facial mask use was increased periodically until reaching $60 \mathrm{~min}$. Subsequently, valves were inserted into the mask, and the same procedure was performed again. Conditioning to the use of the facial masks was performed every other day throughout 2014. From the second week of December 2014, the animals that began to use facial masks every day underwent experimental management.

In January of 2015, when the age of the animals was 19 months, two preliminary experiments were conducted in which the respiratory rate $\left(R_{R}\right.$, breaths $\left.\min ^{-1}\right)$ was determined by counting the movements of the valves for $60 \mathrm{~s}$ for one hour at regular intervals of $10 \mathrm{~min}$ (time: 10, 20, 30, 40, 50 and $60 \mathrm{~min}$ ) after placing the facial mask on the muzzle of an animal. Specifically, these experiments aimed to test whether the use of the facial mask and the experimental routine altered the physiological response of the animals. In this case, the respiratory rate was used as an indicator variable to select animals most suitable for the main experiment. Female animals were distributed in a $9 \times 9$ Latin square (nine animals and nine hours of evaluation) and protected from direct solar radiation. Data were collected from $08: 00 \mathrm{~h}$ to $16: 00 \mathrm{~h}$ for nine consecutive days. The first animal was evaluated between 08:00 $\mathrm{h}$ and 09:00 h, the second between 09:00 $\mathrm{h}$ and 10:00 h, and so on until the last evaluation was conducted between 16:00 $\mathrm{h}$ and 17:00 $\mathrm{h}$. At the end of the study period, all of the animals had been evaluated once in each evaluation time slot. Furthermore, male animals were distributed in a $7 \times 7$ Latin square (seven animals and seven hours of evaluation) and protected from direct solar radiation. The data were collected from $08: 00 \mathrm{~h}$ to $14: 00 \mathrm{~h}$ for seven consecutive days. The first animal was evaluated between 08:00 $\mathrm{h}$ and 09:00 $\mathrm{h}$, the second between 09:00 $\mathrm{h}$ and $10: 00 \mathrm{~h}$, and so on until the last evaluation was conducted between 13:00 $\mathrm{h}$ and 14:00 h. At the end of the study period, all of the animals had been evaluated once in each evaluation time slot.

In February of 2015, based on the results of the preliminary experiments, 10 animals were selected to undergo the main experiment; five females and five males with an average weight of $424 \mathrm{~kg}$ and $367 \mathrm{~kg}$, respectively, were distributed in a $10 \times 10$ Latin square (10 animals and $10 \mathrm{~h}$ of evaluation). The data were collected from $08: 00 \mathrm{~h}$ to $18: 00 \mathrm{~h}$ for 20 consecutive days. The first animal was evaluated between $08: 00 \mathrm{~h}$ and 9:00 $\mathrm{h}$, the second between 9:00 $\mathrm{h}$ and 10:00 $\mathrm{h}$, and so on until the last evaluation was conducted between 17:00 $\mathrm{h}$ and 18:00 h. At the end of the study period, all of the animals had been evaluated once in each evaluation time slot. All of the experiments were performed with the animals protected from direct solar radiation. The animals were separated into individual $12.5-\mathrm{m}^{2}$ stalls and were fed a 60:40 sorghum silage:concentrate diet twice per day at 09:00 h and 15:00 h.

Meteorological variables, including the air temperature $\left(\mathrm{T}_{\mathrm{A}},{ }^{\circ} \mathrm{C}\right)$, relative humidity $\left(\mathrm{H}_{\mathrm{R}}, \%\right)$, partial vapor pressure $\left(\mathrm{P}_{\mathrm{V}}, \mathrm{kPa}\right)$ and mean radiant temperature $\left(\mathrm{T}_{\mathrm{RM}},{ }^{\circ} \mathrm{C}\right)$, were recorded at regular three-minute intervals during each sampling day using a $\mathrm{HOBO}^{\circledR}$ data logger (Onset Computer Corp., Bourne, MA). The air speed ( $A_{S}$, $\mathrm{m} \mathrm{s}^{-1}$ ) data were obtained from the university's meteorological station, which is located near the data collection site. The mean radiant temperature $\left(\mathrm{T}_{\mathrm{RM}},{ }^{\circ} \mathrm{C}\right)$ of the surroundings was estimated by a thermocouple (Type $\mathrm{K}$ ) that was inserted into the center of a hollow $0.15-\mathrm{m}$ diameter copper sphere painted matte black (black globe temperature) placed one meter above the ground, which corresponds to approximately the length of the animal's body from the center to the ground, and close to the animals, according to da Silva and Maia (2013). The local short-wave solar radiation

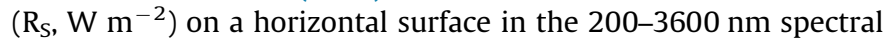
range was measured using a portable pyranometer (Model CMP22, Kipp and Zonen, Delft, Netherlands). The recorded values correspond to the sum of the diffused and direct short-wave radiation and were measured at regular 10 -min intervals during each sampling day.

The volumes $\left(\mathrm{L} \mathrm{s}^{-1}\right)$ of oxygen $\left(\mathrm{VO}_{2}\right)$, carbon dioxide $\left(\mathrm{VCO}_{2}\right)$, and water vapor $\left(\mathrm{H}_{2} \mathrm{O}\right)$ in the exhaled air of the cattle were measured using an indirect calorimetry system coupled to the facial mask adjusted to the animals' muzzles (Fig. 1), which were similar to those used by Maia et al. (2016). The facial mask was designed to ensure that the volume of ventilated dead space $\left(V_{d}\right)$ was as close to zero as possible because it affects the true concentration of the expired gases (McLean, 1963). The mask was constructed with the lowest possible $V_{d}\left(V_{d} \rightarrow 0\right)$; hence, the ratio $(K)$ of the respiratory tidal volume $\left(V_{T}\right)$ to $V_{d}\left(K=V_{d} / V_{T}\right)$ was maximized. The best geometry of the facial mask that reduced the $\mathrm{V}_{\mathrm{d}}$ was an ellipsoidal shape with a $\mathrm{V}_{\mathrm{d}}$ of approximately $0.2 \mathrm{~L}$ (Maia et al., 2014).

During each breath, the inflow (inspired air) and outflow (exhaled air) passed through two valves. The exhaled air from the facial mask was directed through a tracheal tube (MLA1015, ADInstruments, Australia) to a gas-mixing chamber (MLA246, ADInstruments, Australia). The gas-mixing chamber was connected to a field metabolic system (FMS; Sable Systems, USA) by a plastic tube (Bev-A-Line, Sable Systems, USA). An air pump at the FMS maintained a continuous flow of exhaled air $\left(150 \mathrm{~mL} \mathrm{~min}^{-1}\right)$ through this tube and into a gas analyzer for the measurement of $\mathrm{H}_{2} \mathrm{O}, \mathrm{O}_{2}$, and $\mathrm{CO}_{2}$. The air sample passed through a $\mathrm{H}_{2} \mathrm{O}$ vapor analyzer, a dryer (utilizing a $\mathrm{Mg}\left(\mathrm{ClO}_{4}\right)_{2}$ desiccant), $\mathrm{CO}_{2}$ and $\mathrm{O}_{2}$ analyzers and, finally, a $\mathrm{CH}_{4}$ analyzer (MA-10, Sable Systems, USA). Air leaving the mixing chamber passed through a flow head (MLT 1000, ADInstruments, Australia) coupled to a spirometer ( $\mathrm{mL} 141$, ADInstruments, Australia), which measured the respiratory rate $\left(\mathrm{R}_{\mathrm{R}}\right.$, breaths $\left.\mathrm{min}^{-1}\right)$ and ventilation $\left(\mathrm{V}_{\mathrm{E}}, \mathrm{Ls}^{-1}\right)$. The FMS, $\mathrm{CH}_{4}$ analyzer, spirometer, $\mathrm{H}_{2} \mathrm{O}$ vapor analyzer, and thermocouples were connected to a data acquisition system (PowerLab 16/32, ADInstruments, Australia), which was connected to a computer that continuously and simultaneously recorded all of the measurements at a rate of one observation per second. The proportions of oxygen and carbon dioxide in the atmosphere $\left(\mathrm{O}_{2 \mathrm{~A}}\right.$ and $\mathrm{CO}_{2 \mathrm{~A}}$, respectively) were analyzed by the FMS. These measurements were performed whenever the facial mask was placed on an animal's muzzle. The atmospheric vapor pressure $\left(\mathrm{P}_{\mathrm{v}}, \mathrm{kPa}\right)$ was continuously recorded by an external $\mathrm{H}_{2} \mathrm{O}$ vapor analyzer (RH-300, Sable Systems, USA) connected to a pump (SS4, Sable Systems, USA), which continuously aspirated samples of atmospheric air $\left(150 \mathrm{~mL} \mathrm{~min}^{-1}\right.$ ) from near the mask's influx valve.

The hair coat surface temperature $\left(\mathrm{T}_{\mathrm{S}},{ }^{\circ} \mathrm{C}\right)$ was measured with a sensor (MLT 422A, ADInstruments, Australia; accuracy: $\pm 0.3^{\circ} \mathrm{C}$, height $\times$ diameter: $4.0 \times 9.7 \mathrm{~mm}$ and thermal response time: still 


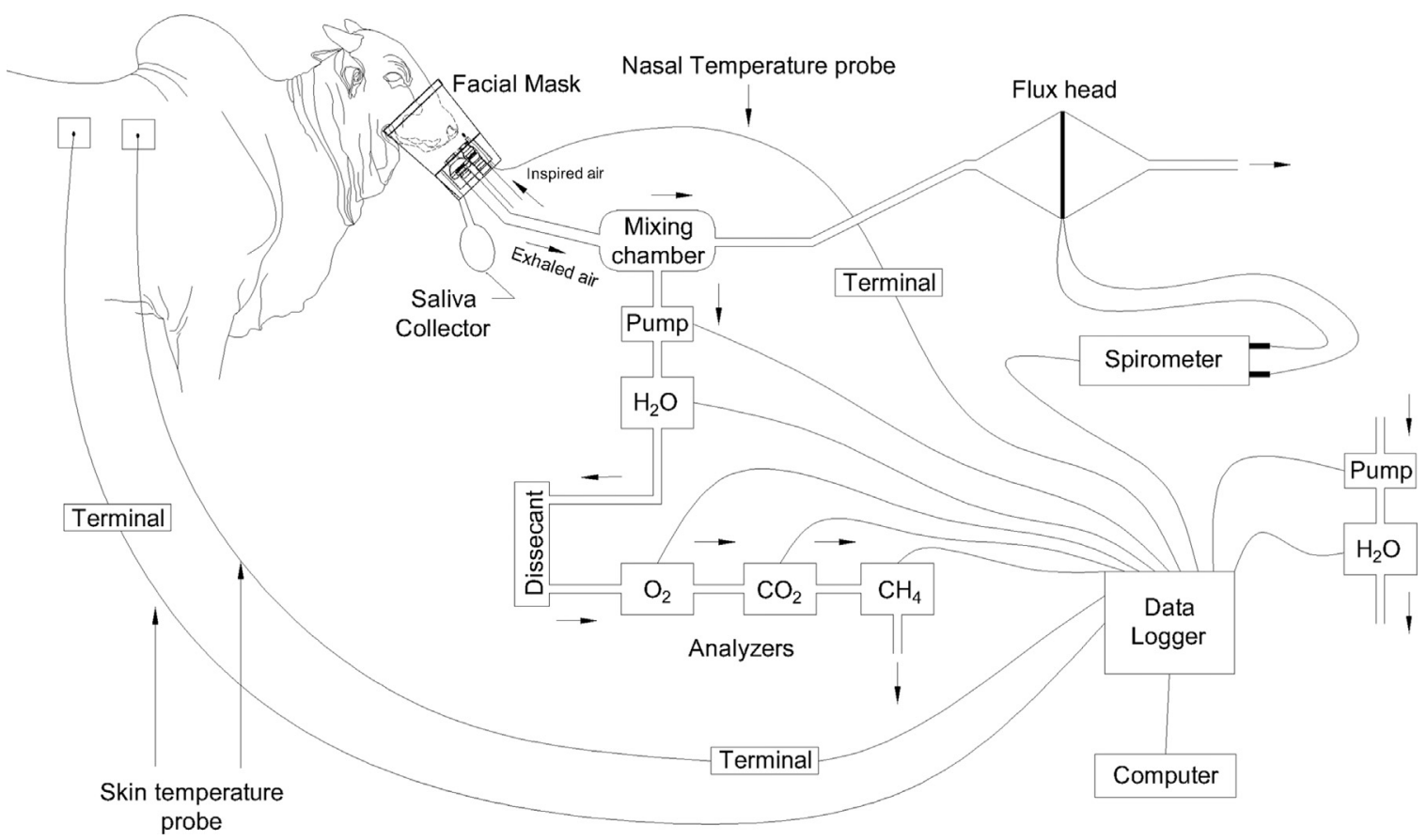

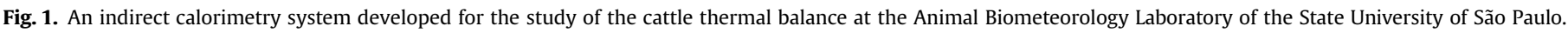

air $45 \mathrm{~s}$ ) that was placed on the back of the animal on the hair coat surface. Approximately $10 \mathrm{~cm}$ away from the hair-coat temperature sensor, another similar sensor was used to measure the skin surface temperature $\left(\mathrm{T}_{\mathrm{EP}},{ }^{\circ} \mathrm{C}\right)$; however, in this case, the skin area was previously shaved. These sensors were fixed on the animal's skin using a plastic board (length $\times$ width $\times$ height: $6.0 \times 4.0 \times 0.1 \mathrm{~cm}$ with a thermal conductivity of approximately $0.036 \mathrm{~W} \mathrm{~m}^{-1} \mathrm{~K}^{-1}$ ) with the aid of an elastic belt around the animal's upper body. The rectal temperature $\left(\mathrm{T}_{R},{ }^{\circ} \mathrm{C}\right)$ was continuously recorded by a rectal thermocouple (MLT 1404, ADInstruments, Australia, Accuracy $\pm 0.3^{\circ} \mathrm{C}$ ). A nasal temperature sensor (MLT 415/AL, ADInstruments, Australia, Accuracy $\pm 0.3^{\circ} \mathrm{C}$ ) was placed inside the facial mask just in front of the animal's nostrils to measure the exhaled air temperature $\left(\mathrm{T}_{\mathrm{EXP}},{ }^{\circ} \mathrm{C}\right)$.

The volumes of $\mathrm{O}_{2}, \mathrm{CO}_{2}$, and $\mathrm{CH}_{4}\left(\mathrm{~L} \mathrm{~s}^{-1}\right)$ were calculated according to McLean (1972) using the Haldane transformation:

$$
\begin{aligned}
& \mathrm{VO}_{2}=\mathrm{V}_{\mathrm{E}}\left[\mathrm{O}_{2 \mathrm{~A}}\left(\frac{1-\mathrm{O}_{2 \mathrm{~A}}-\mathrm{CO}_{2 \mathrm{~A}}-\mathrm{CH}_{4 \mathrm{~A}}}{1-\mathrm{O}_{2 \mathrm{E}}-\mathrm{CO}_{2 \mathrm{E}}-\mathrm{CH}_{4 \mathrm{E}}}\right)-\mathrm{O}_{2 \mathrm{E}}\right] \\
& \mathrm{VCO}_{2}=\mathrm{V}_{\mathrm{E}}\left[\mathrm{CO}_{2 \mathrm{E}}-\mathrm{CO}_{2 \mathrm{~A}}\left(\frac{1-\mathrm{O}_{2 \mathrm{~A}}-\mathrm{CO}_{2 \mathrm{~A}}-\mathrm{CH}_{4 \mathrm{~A}}}{1-\mathrm{O}_{2 \mathrm{E}}-\mathrm{CO}_{2 \mathrm{E}}-\mathrm{CH}_{4 \mathrm{E}}}\right)\right] \\
& \mathrm{VCH}_{4}=\mathrm{V}_{\mathrm{E}}\left[\mathrm{CH}_{4 \mathrm{E}}-\mathrm{CH}_{4 \mathrm{~A}}\left(\frac{1-\mathrm{O}_{2 \mathrm{~A}}-\mathrm{CO}_{2 \mathrm{~A}} \mathrm{CH}_{4 \mathrm{~A}}}{1-\mathrm{O}_{2 \mathrm{E}}-\mathrm{CO}_{2 \mathrm{E}}-\mathrm{CH}_{4 \mathrm{E}}}\right)\right]
\end{aligned}
$$

The metabolic heat production ( $\mathrm{q}^{\prime \prime}{ }_{\text {met }}, \mathrm{W} \mathrm{m}^{-2}$ ) was calculated in accordance with the equation of da Silva and Maia (2013) as adapted from Brouwer (1965) and McLean (1972):

$q_{\text {met }}^{\prime \prime}=\frac{16180 \mathrm{VO}_{2}+5160 \mathrm{VCO}_{2}-2420 \mathrm{VCH}_{4}}{\mathrm{~A}_{\mathrm{n}}}$

where $A_{n}=0.15 B_{W}{ }^{0.556}\left(\mathrm{~m}^{2}\right)$ is the body surface area of the animal, estimated according to Finch (1985), and $\mathrm{B}_{\mathrm{W}}$ is the animal body weight $(\mathrm{kg})$. The respiratory latent heat flow $\left(\mathrm{q}_{\mathrm{er}}^{\mathrm{e}}, \mathrm{W} \mathrm{m}^{-2}\right)$, heat exchange by long-wave radiation $\left(\mathrm{q}_{\mathrm{rl}}, \mathrm{W} \mathrm{m}^{-2}\right.$ ) and convection ( $\mathrm{q}^{\prime \prime}$ conv, $\mathrm{W} \mathrm{m}^{-2}$ ) were calculated according to Maia et al. (2016).

\subsection{Statistical analyses}

The data set from the preliminary experiments was collected according to a plan (Latin Squares) with multiple measurements of a response variable (respiratory rate) on the same experimental unit (animal) conducted over a period (within-subjects factor). Typically, the animal-by-time interaction was the main effect used to choose the 10 animals to undergo the main experiment. The data of the repeated measures were analyzed using mixed model methods based on generalized least squares and a variance component estimation, which were performed by a restricted maximum likelihood (REML) algorithm with a procedure for a linear mixed model (PROC MIXED) of the Statistical Analysis System (SAS Institute, 1995) according to Littell et al. (2006). The linear statistical model used to describe the respiration rate was as follows:

$$
\begin{aligned}
Y_{i j k l m}= & \mu+S_{i}+D(S)_{i j}+H_{k}+A(S)_{i l}+A(S D H)_{i j k l}+T_{m}+(S T)_{i m} \\
& +T A(S)_{i l m}+T D(S)_{i j m}+e_{i j k l m}
\end{aligned}
$$

where $Y_{i j k l m}$ denotes the response from the experimental unit (animal) observed in hour class $k$, in sample day $j$, and in sex $i ; S$ is the fixed effect of the $i$ th sex ( $i=$ male or female); $D(S)$ is the random effect of the $j$ th sample day within of the $i$ th sex $(i=$ male, then $j=1,2 \ldots 7 ; i=$ female, then $j=8,9 \ldots 16$ ); $H$ is the fixed effect of the $k$ th hour class $(k=8: 00-9: 00 \mathrm{~h} ; 9: 00-10: 00 \mathrm{~h}$; and so forth until 16:00-17:00 h); $A(S)$ is the fixed effect of the lth animal within in the $i$ th sex $(i=$ female, then $l=1,5,9,11,13,15,17,19$ and $21 ; i=$ male, then $l=2,4,6,8,10,12$ and 14$) ; A(S D H)$ is the random effect of the lth animal within the interaction of the ith sex with the $j$ th sample day and with the $k$ th hour class; $T$ is the fixed effect of the $m$ th time ( $m=10,20,30,40,50$ and $60 \mathrm{~min})$; $S T$ is the interaction between the $i$ th sex with the $m$ th time; $T A(S)$ is the interaction between the $m$ th time with the $l$ th animal within in the $i$ th sex; $T D(S)$ is the interaction between the $m$ th time with the $j$ th sample day within in the $i$ th sex; $e_{i j k l m}$ is the residual term, including the random error, which was assumed independent and distributed identically to iid $N\left(0, \sigma^{2}\right)$; and $\mu$ is the overall mean.

As noted in the repeated measures data, it is very important to appropriately adjust the model for the covariance structure 

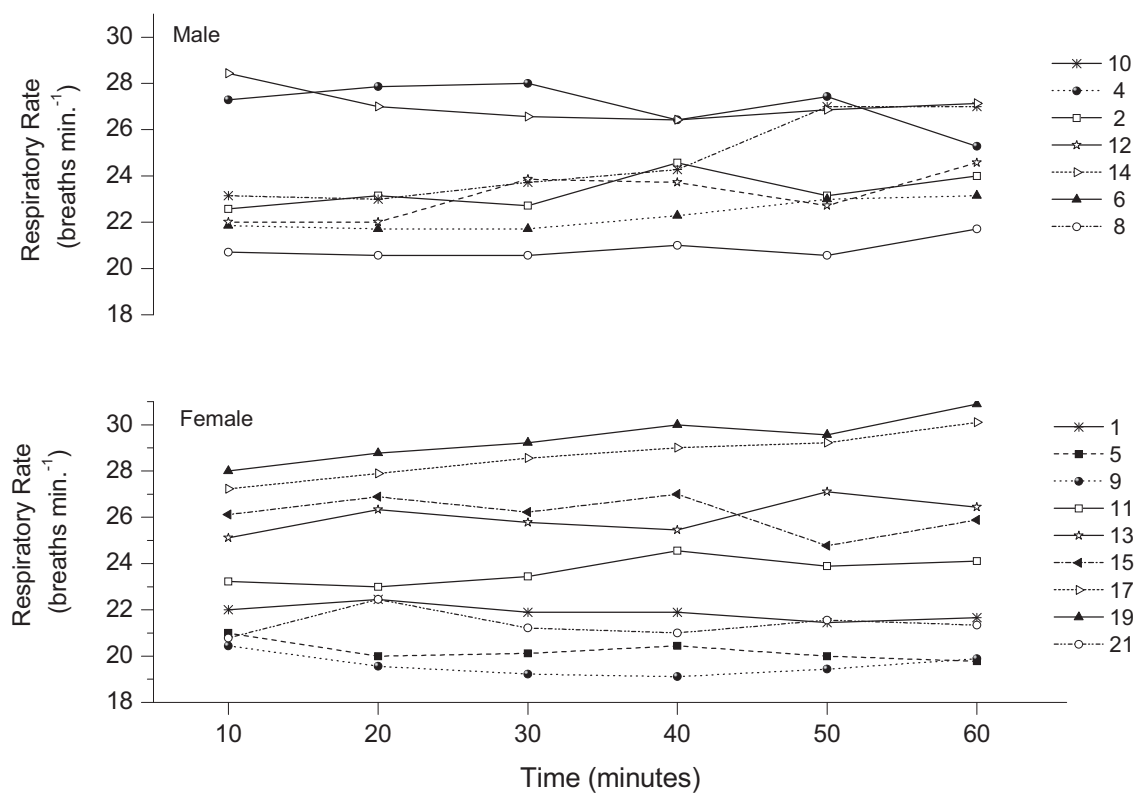

Fig. 2. Least square mean values of the respiratory rate of male and female Guzerat cattle according to the time of use of the facial mask.

because the inferential results regarding fixed effects depend on the specification of the covariance matrix of the random effects (Littell et al., 2006). In this work, for the unstructured case (UN), the constructed covariance matrix $(\Sigma)$ reveals the essential feature of the repeated measures data (within subjects), where the estimates of the variances at time 10 through 60 were increasing linearly, whereas the covariance estimates demonstrate that measures taken close in time had the same covariance as the measures that were far apart in time. These results suggest that $\Sigma$ with a constant covariance and a trend of increasing variance over the time of observation is probably adequate. Based in these results, it was possible to test other covariance structures; this process is called heterogeneous compound symmetry (HCS). The fit statistics of Akaike's information criterion (AIC), AIC corrected (AICC), and Bayesian information criterion (BIC) were smaller for HCS than for UN, verifying the superior fit of the HCS structure compared to the UN structure.

The data set from the main experiment was collected according to a plan (Latin Squares), but the treatments were not applied to the units. Instead, they were applied to an animal of a different sex; consequently, these sample surveys measured the effect of this factor on and the association with other factors. In other words, we questioned whether there was a sex effect, an hour effect, an air temperature effect, and a sex-by-hour or sex-by-air temperature interaction. To answer these questions, the data were analyzed using mixed model methods based on generalized least squares, a variance components estimation that was performed with a restricted maximum likelihood (REML) algorithm, and a procedure of a linear mixed model (PROC MIXED) from the Statistical Analysis System (SAS Institute, Version 8) according to Littell et al. (2006). The linear statistical model used to describe $R_{R}$, $V_{E}, T_{S}, T_{E}, T_{E X P}, T_{R}, q^{\prime \prime}$ met, q"er and q"sen was as follows:

$$
\begin{aligned}
Y_{i j k l m n o}= & \mu+L_{i}+D(L)_{i j}+H_{k}+F(H)_{k l}+S_{m}+A(S)_{m n}+(H S)_{k m} \\
& +A(L D H S)_{i j k l m n}+T_{o}+(S T)_{m o}+e_{i j k l m n o}
\end{aligned}
$$

where $Y_{i j k l m n o}$ denotes the response from the experimental unit (animal) observed in the class air temperature $o$, in the sex $m$, in the hour class $k$, in sample day $j$, and in the Latin square $i$; $L$ is the random effect of the $i$ th Latin squares (1 or 2); D is the random effect of the $j$ th sample day within the $i$ th Latin squares (if $i=1$, then $j=1,2 \ldots 10$; if $i=2$, then $j=11,12 \ldots 20)$; $\mathrm{H}$ is the fixed effect of the $k$ th hour class $(k=8: 00-9: 00 \mathrm{~h} ; 9: 00-10: 00 \mathrm{~h}$; and so forth until 17:00-18:00 h); F is the fixed effect of the lth time within the $k$ th hour class $(k=8: 00-9: 00$, then $l=8: 00,8: 05,8: 10,8: 15, \ldots$, $8: 55$; if $k=9: 00-10: 00$, then $l=9: 00,9: 05,9: 10,9: 15, \ldots, 9: 55$; and so forth until $k=17: 00-18: 00$, then $l=17: 00,17: 05,17: 10,17: 15, \ldots$, 17:55); $\mathrm{S}$ is the fixed effect of the $m$ th sex ( $m=$ male or female); A is the random effect of the $n$th animal within in the $m$ th sex ( $m=$ female, then $n=1,2, \ldots, 5 ; m=$ male, then $n=6,7, \ldots, 10$ ); HS is the interaction between the $k$ th hour class with the $m$ th sex; A (LDHS) is the random effect of the $n$th animal within the interaction of the $i$ th Latin squares with the $j$ th sample day with the $k$ th hour class and with the $m$ th sex; $T$ is the fixed effect of the oth class of air temperature $\left(23=\mathrm{T}_{\mathrm{A}} \leq 23.5^{\circ} \mathrm{C}\right.$; $24=23.5^{\circ} \mathrm{C}<\mathrm{T}_{\mathrm{A}} \leq 24.5^{\circ} \mathrm{C}$; and so forth until $\left.35=\mathrm{T}_{\mathrm{A}}>34.5^{\circ} \mathrm{C}\right)$; $\mathrm{ST}$ is the interaction between the $m$ th sex with the oth class of air temperature; $e_{i j k l m n o}$ is the residual term, including the random error, which was assumed to be independent and distributed identically to iid $N\left(0, \sigma^{2}\right)$; and $\mu$ is the overall mean.

Based on the data set of the preliminary experiment, 10 animals were chosen (five male and five female) whose respiration rate did not greatly change during $60 \mathrm{~min}$ of using the facial mask. To make this selection, Principal Component analysis (Mainly, 1994; Johnson, 1998) was used to separate the animals into groups based on the available respiration rate at time 10, 20, 30, 40, 50 and $60 \mathrm{~min}$. The principal components were obtained by computing the eigenvalues and eigenvectors of the data covariance matrix. A bidimensional representation of this multidimensional set was created for the principal components that accumulated a significant percentage of original information. The principal components with significant contributions were those with eigenvalues greater than 1. Principal Component analysis were used to understand whether the physiological responses were different between males and females, and if they were, it was used to determine which variables contributed more to the difference. This analysis was performed using the STATISTICA 7.0 software (STATSOFT, INC., 2007).

\section{Results and discussion}

The variance analyses for the preliminary experiment showed that the interaction time with an animal within the same sex was 


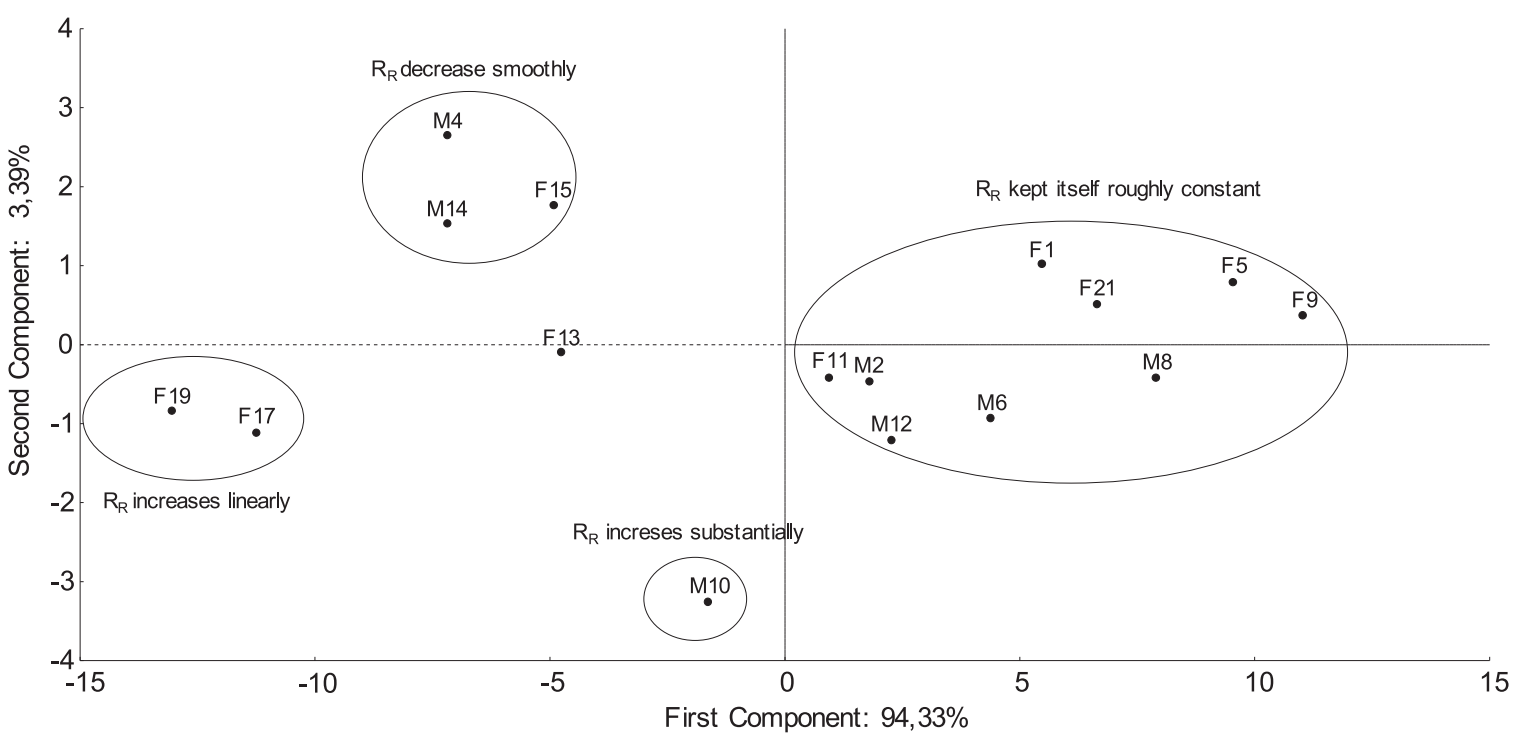

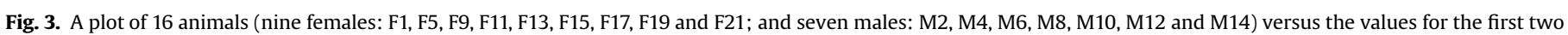
principal components. $R_{R}$ is the respiratory rate.

Table 1

Mean of the air temperature $\left(\mathrm{T}_{\mathrm{A}}\right)$, relative humidity $\left(\mathrm{H}_{\mathrm{R}}\right)$, mean radiant temperature $\left(T_{R M}\right)$, solar irradiation $\left(R_{S}\right)$ and partial pressure of vapor $\left(P_{P}\left\{T_{A}\right\}\right)$ observed in Ilha Solteira, SP, Brazil during February 2015 from 8:00 to 18:00.

\begin{tabular}{llccc}
\hline Variable & $\mathrm{N}$ & \multicolumn{1}{l}{ Mean } & Minimum & Maximum \\
\hline $\mathrm{T}_{\mathrm{A}}\left({ }^{\circ} \mathrm{C}\right)$ & 11,940 & $29.8 \pm 0.03$ & 22.8 & 36.4 \\
$\mathrm{H}_{\mathrm{R}}(\%)$ & 11,940 & $66.9 \pm 0.11$ & 43.7 & 91.3 \\
$\mathrm{~T}_{\mathrm{RM}}$ shade $\left({ }^{\circ} \mathrm{C}\right)$ & 11,048 & $30.0 \pm 0.04$ & 23.82 & 37.2 \\
$\mathrm{R}_{\mathrm{S}}\left(\mathrm{W} \mathrm{m}{ }^{-2}\right)$ & 10,030 & $562.4 \pm 2.84$ & 23.0 & 1195.00 \\
$\mathrm{P}_{\mathrm{P}}\left\{\mathrm{T}_{\mathrm{A}}\right\}(\mathrm{kPa})$ & 11,846 & $2.18 \pm 0.03$ & 1.55 & 3.02 \\
\hline
\end{tabular}

$\mathrm{N}=$ number of observations.

highly significant ( $\mathrm{p}<0.01$ ). Fig. 2 shows the respiratory rate mean values estimated by the least squares for each animal over the six tested times and shows trends in the animal mean profiles for both sexes. As noted, the respiration rate mean values among the animals varied. These ranges occurred from approximately 20 to less than 30. In addition, the means for the respiration rate for each animal did not substantially change from time 10 to time 60 , independent of sex (approximately less than five breaths). For example, female 1 and 21 did not change from time 10 to time 60, while female 19 and 17 had a higher $R_{R}$, which increased slightly over time. In the group of males, it can also be observed in Fig. 2 that animal 10 showed the greatest increase in $R_{R}$ over time and that there was a difference between the other males. In addition to these results, to ensure the choice of animals with the same pattern, a principal components analysis was conducted (Fig. 3), which clearly showed four groups: the first was formed by animals that maintained a fairly constant $R_{R}$, the second was formed by animals that had a smoothly decreasing $R_{R}$, the third was formed by animals that had a linearly increasing $R_{R}$ and the fourth was formed by animals that had a substantially increased $R_{R}$. This sequence determined the choice of animals for the main experiment; however, females 5 and 9 were not selected. The selection of these animals occurred through the observation of other behaviors, such as the difficulty of processing these animals from the pen to the restraining chute and their reactivity; therefore, two other females, F15 and F13, were substituted.

The data observed for expiration, hair-coat surface and skin

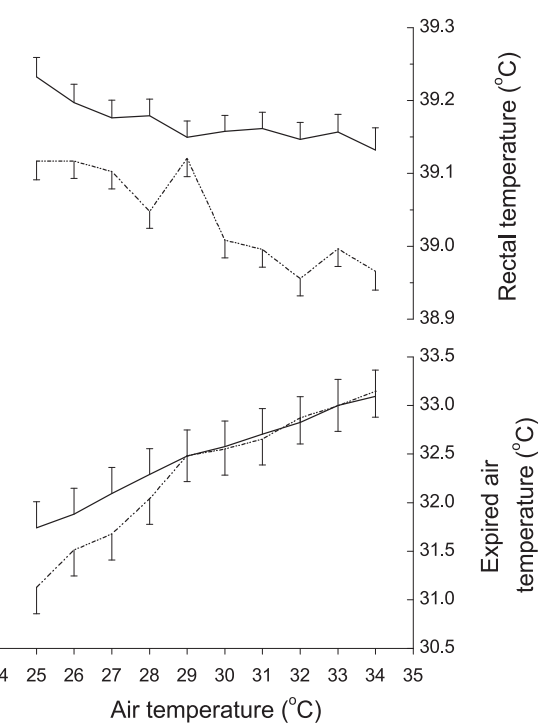

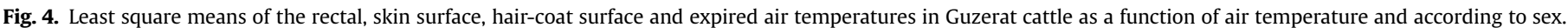
The vertical bars are the mean standard error. 


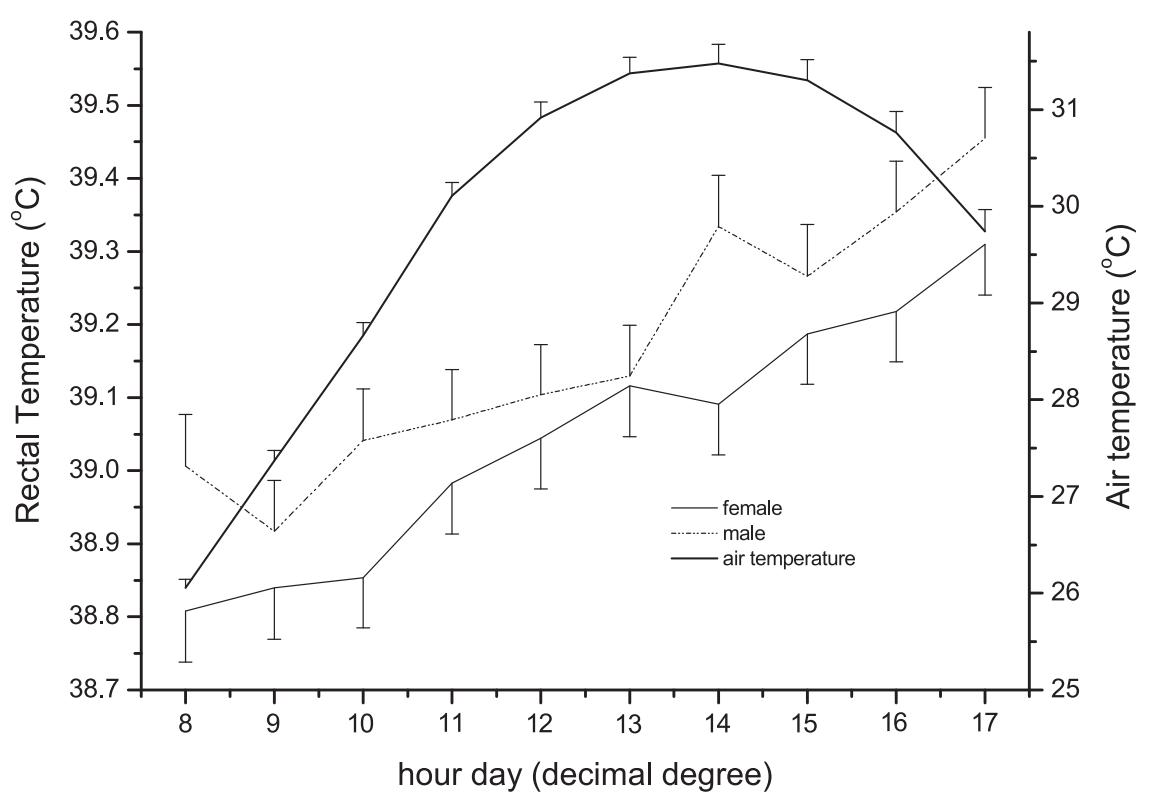

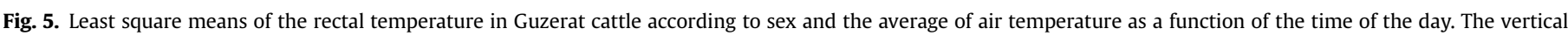
bars are the mean standard error.

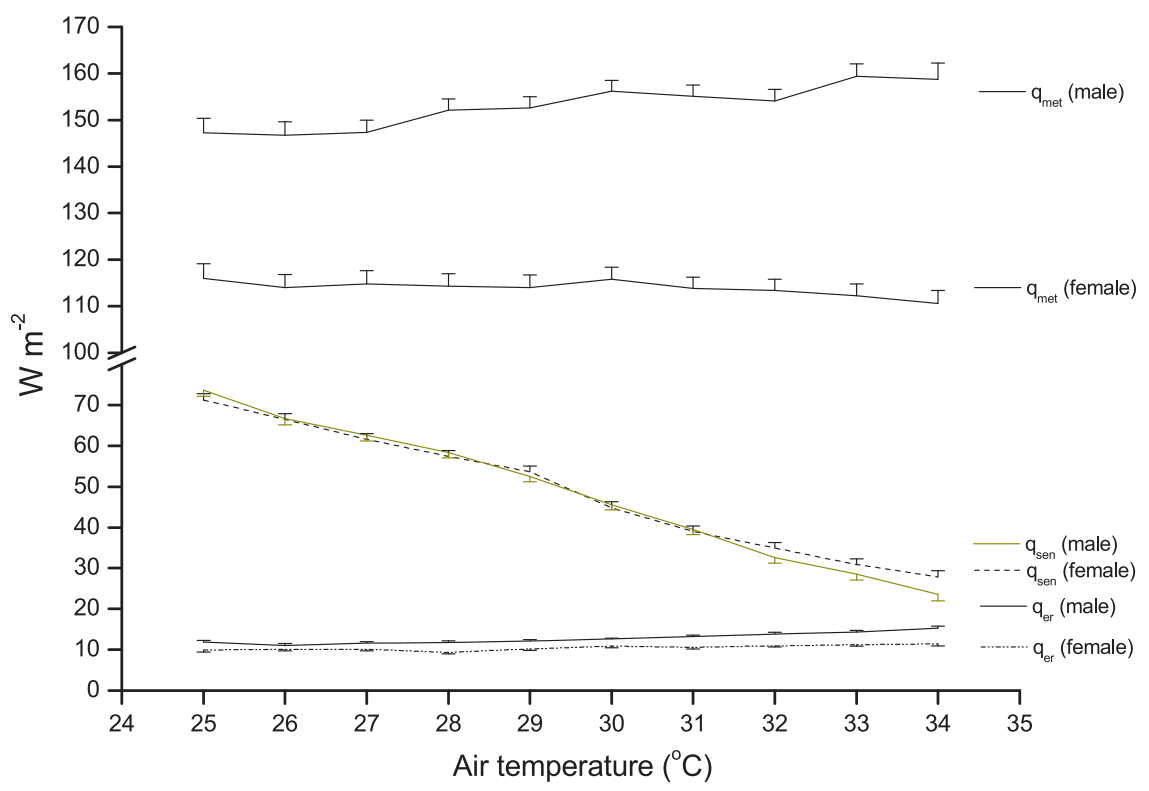

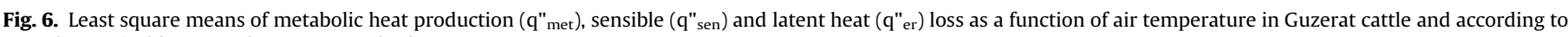
sex. The vertical bars are the mean standard error.

surface temperature increased from approximately 28 to $35^{\circ} \mathrm{C}, 31$ to $38^{\circ} \mathrm{C}$ and 33 to $38^{\circ} \mathrm{C}$, respectively, following the substantial variation of the air temperature, solar radiation and air humidity (Table 1). Similar to the increases reported by Brown-Brandl et al. (2006), working with Angus cattle during two consecutive summers (2002-2003) in the USMARC feedlot located $9.6 \mathrm{~km}$ west and $3.2 \mathrm{~km}$ north of Clay Center, Nebraska, increases in the skin surface temperature of up to $8{ }^{\circ} \mathrm{C}$ between mornings and afternoons were observed. Similarly, Gebremedhin et al. (2010), in a study of Holstein cows in climate chambers, showed that the skin surface temperature increased from 33.1 to $37.9{ }^{\circ} \mathrm{C}$ when the $\mathrm{T}_{\mathrm{A}}$ increased from 29.1 to $35.1^{\circ} \mathrm{C}$.

The variance analyses showed that the interaction between the air temperature class and sex was significant $(p<0.01)$ for temperatures that were less than the rectal temperature. Fig. 4 indicates that the means for the hair-coat and skin surface and expired air temperatures increased with increased air temperature, with the means for females being lower that the means for males. The profiles for the rectal temperature generally appeared to decrease from an air temperature of $25{ }^{\circ} \mathrm{C}$ to an air temperature of $34{ }^{\circ} \mathrm{C}$ (however, the trend was generally stable). The rectal temperature range was from approximately 0.2 and $0.1^{\circ} \mathrm{C}$ for females and males, respectively. The decreasing trend is more obvious in this plot because of the difference in the scale of the rectal temperature axis.

However, the variance analyses showed that the interaction between the hour class and sex was significant $(p<0.01)$ for the rectal temperature. This value increased slowly and continuously over time, increasing from mean values of 38.7 to $39.3{ }^{\circ} \mathrm{C}$ and 38.9 to $39.5^{\circ} \mathrm{C}$ at $8: 00 \mathrm{~h}$ and $18: 00 \mathrm{~h}$, for females and males, 


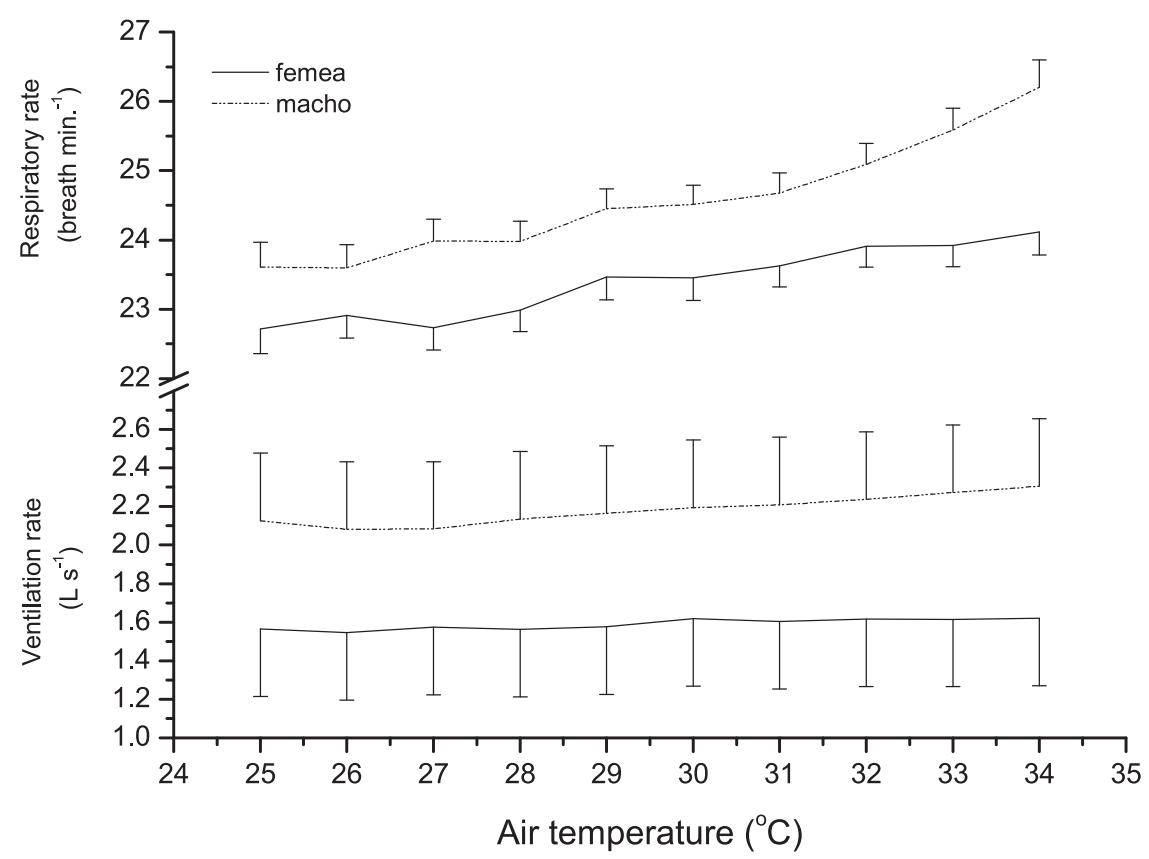

Fig. 7. Least square means of the respiration rate and ventilation rate as a function of air temperature in Guzerat cattle and according to sex. The vertical bars are the mean standard error.

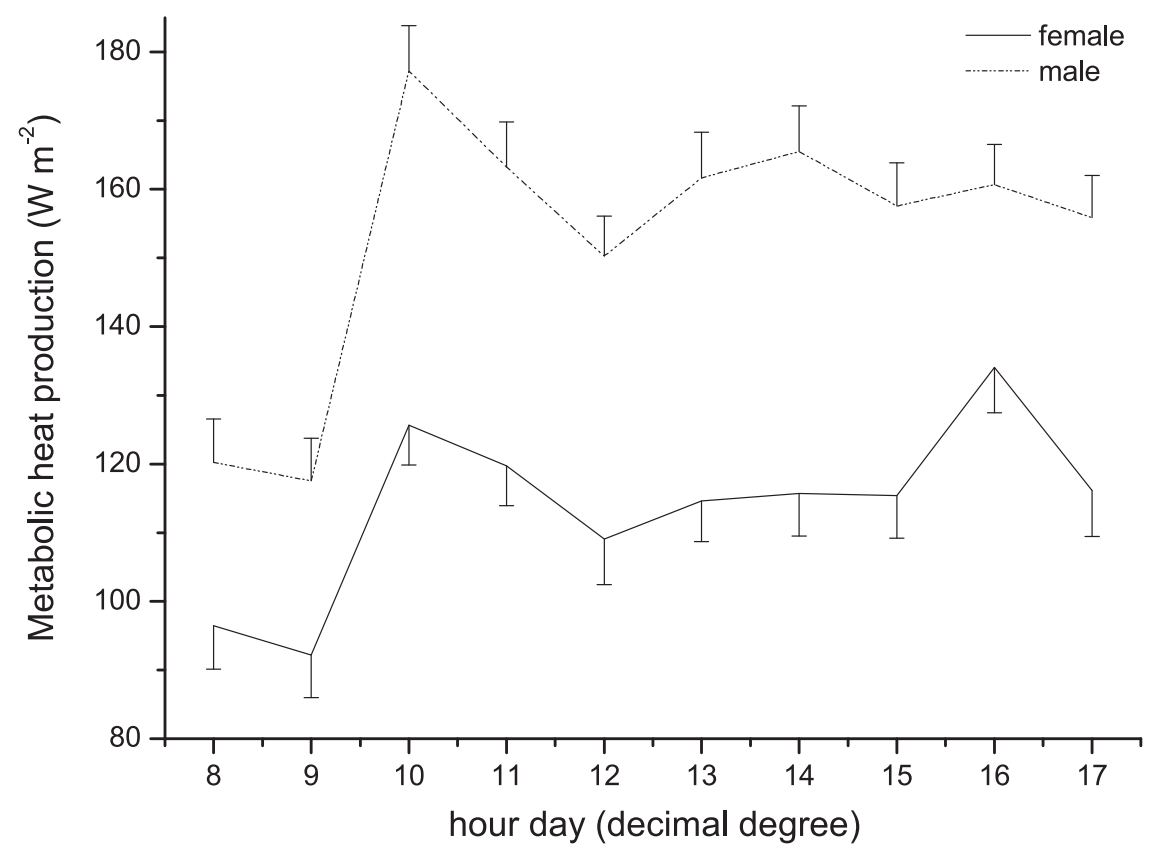

Fig. 8. Least square means of metabolic heat production as a function of the time of day in Guzerat cattle. The vertical bars are the mean standard error.

respectively (Fig. 5). The continual increase in rectal temperature during the day was in contrast to the variation of air temperature. The mean values for air temperature increased substantially from 25 to $31.5{ }^{\circ} \mathrm{C}$ between $8: 00 \mathrm{~h}$ until $13: 00 \mathrm{~h}$. After this time and until approximately $15: 00 \mathrm{~h}$, the rectal temperature was generally flat near $31.5^{\circ} \mathrm{C}$; however, between $15: 00 \mathrm{~h}$ and $18: 00 \mathrm{~h}$, it declined. We questioned why the rectal temperature continued to increase over this time interval. These results were also observed by Costa (2013), who worked with Nellore cattle. These results can be related to heat storage during the day (McLean, 1963), which is then dissipated at night by convection and long-wave radiation (Mclean et al., 1983; Schmidt-Nielsen, 2013). Piccione et al. (2005), who worked with crossbred cattle (1/4 Angus, 1/4 Hereford, 1/4 Pinzgauer, and $1 / 4$ Red Poll), found similar increases in the rectal temperature with the time of day. Studying the same animals, BrownBrandl et al. (2003) reported an identical pattern, with a maximum rectal temperature of $40.6{ }^{\circ} \mathrm{C}$ at $17: 30 \mathrm{~h}$ and a minimum temperature of $39.1{ }^{\circ} \mathrm{C}$ at $5: 30 \mathrm{~h}$.

The variance analyses showed that the interaction between the air temperature class and sex was not significant $(p>0.01)$ for sensible and latent heat loss. In both sexes (Fig. 6), the mean sensible heat flow decreased substantially from 70 to $20 \mathrm{~W} \mathrm{~m}^{-2}$. This result occurred because the temperature gradient $\left(\Delta=\mathrm{T}_{\mathrm{S}}-\mathrm{T}_{\mathrm{A}}\right)$ decreased from 9 to $2{ }^{\circ} \mathrm{C}$. As noted in Fig. 6, the mean values of the 


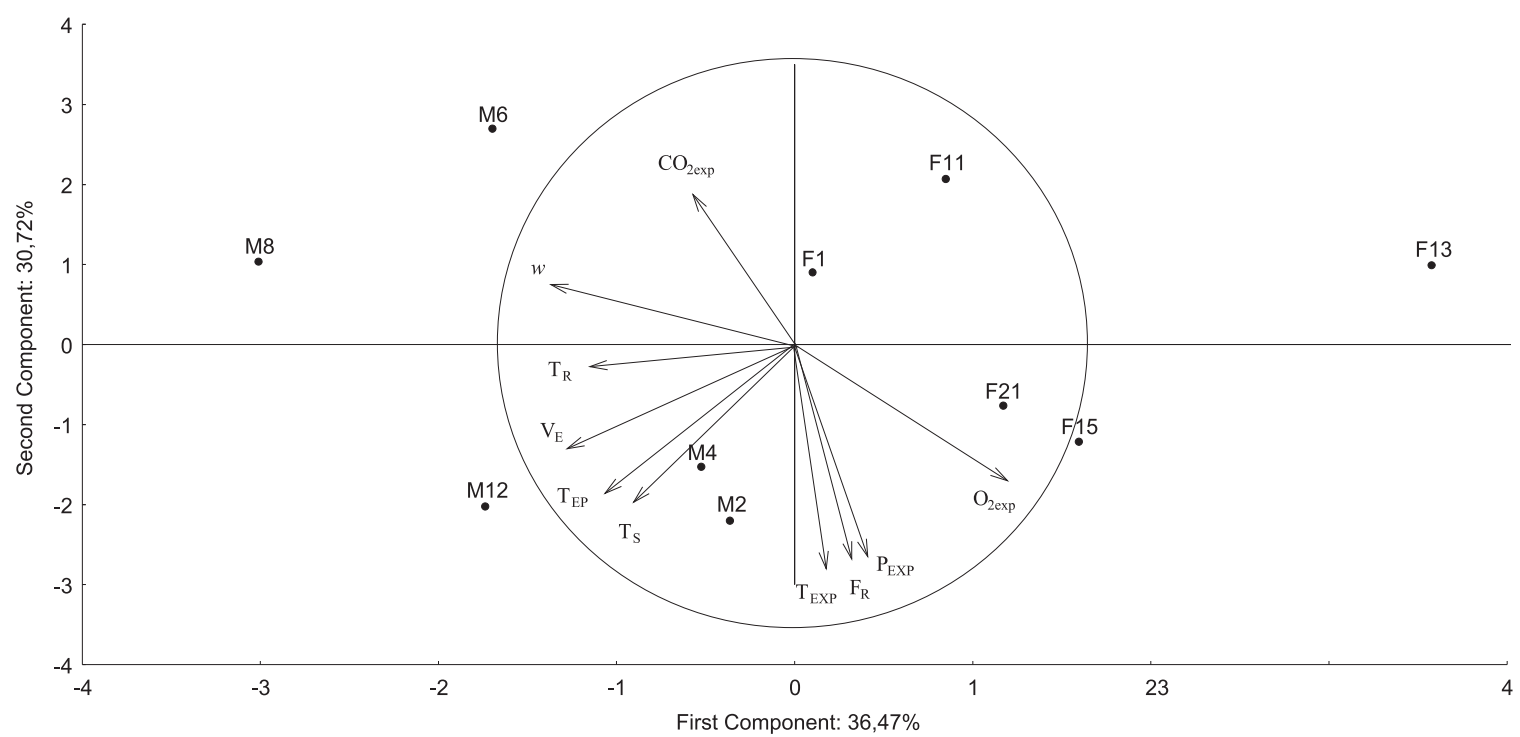

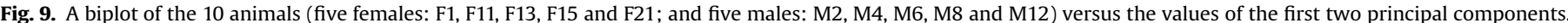

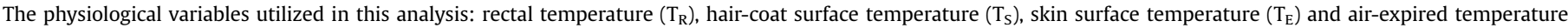
$\left(\mathrm{T}_{\mathrm{EXP}}\right)$; respiration rate $\left(\mathrm{R}_{\mathrm{R}}\right)$, ventilation rate $\left(\mathrm{V}_{\mathrm{E}}\right)$, \% of oxygen $\left(\mathrm{O}_{2 \exp }\right)$ and carbon dioxide $\left(\mathrm{CO}_{2 \exp }\right)$ in air expired; body weight $(w)$ and air-expired vapor pressure $\left(\mathrm{P}_{\mathrm{EXP}}\right)$.

respiratory latent heat flow did not substantially change when the air temperature increased from 24 to $34^{\circ} \mathrm{C}$, and its maximum value was approximately $15 \mathrm{~W} \mathrm{~m}^{-2}$. This value represents less than $10 \%$ of the heat produced by metabolism (Fig. 6). However, Maia et al. (2005), in a study with Holstein cows, observed an increase from 10 to $60 \mathrm{~W} \mathrm{~m} \mathrm{~m}^{-2}$ when the air temperature increased from 10 to $35^{\circ} \mathrm{C}$.

Previous studies showed that animals could promote heat loss via respiratory evaporation by increasing their ventilation, which demands a faster breathing rate (Robertshaw, 2006). The results (Fig. 7) indicate that the mean for the respiratory rate was low and increased weakly in females and males from 22 to 24 and 23 to 26 breaths $\mathrm{min}^{-1}$, respectively, as the air temperature increased from 25 to $34^{\circ} \mathrm{C}$, with the mean values for females being slightly less than those for males (only two breaths on average). Brown-Brandl et al. (2003), working with crossbred cattle ( $1 / 4$ Angus, $1 / 4$ Hereford, $1 / 4$ Pinzgauer, and $1 / 4$ Red Poll) in climate chambers, reported an increase in the respiratory rate from 55.6 to 103 breaths $\min ^{-1}$ as air the temperature increased from 17.5 to $34.0^{\circ} \mathrm{C}$. Eigenberg et al. (2005), in a study with the same crossbred cattle, observed a difference in the average respiratory rate between protected animals ( 86 breaths $\min ^{-1}$ ) and animals exposed to direct solar radiation (102 breaths $\mathrm{min}^{-1}$ ).

Fig. 6 demonstrates that the metabolic heat production remained stable, regardless of the variation in the air temperature from 25 to $34{ }^{\circ} \mathrm{C}$. The same result was found for the respiration rate (Fig. 7). However, the variance analyses showed that the sex effect was significant $(p<0.01)$ for these variables. In males, the ventilation rate and heat metabolic production were approximately $25-30 \%$ higher than those of females (Fig. 5). The ventilation rate mean was 1.6 and $2.2 \mathrm{~L} \mathrm{~s}^{-1}$ for females and males, respectively, whereas the heat metabolic production was 115 and $155 \mathrm{~W} \mathrm{~m}^{-2}$, respectively.

Fig. 8 shows that the metabolic heat production differs between males and females during the $10 \mathrm{~h}$ of the experiment and is always higher for males. This can be explained by the $V_{E}$ difference between the sexes (Fig. 7), as males have a $V_{E}$ approximately $25 \%$ higher than females. When this does not occur with the respiratory rate (where it appears that the difference between the sexes is only a breath per minute), the difference is approximately $5 \%$. When the magnitude of the variation between $V_{E}$ and $R_{R}$ is different, the effect of each of the metabolic heat productions mechanisms is shown. Still, in Fig. 8, it is noted that there was a substantial increase in metabolic heat production after $9 \mathrm{~h}$, which can be explained by the time the food was given to the animals, as evidenced by Brosh et al. (1998) and West (1994).

As noted in Fig. 9, the first component separated the animals into two groups (male and female). The first and second components explain $36.7 \%$ and $30.72 \%$, respectively, of the total variation of the original variables (Fig. 9). The variables $V_{E}, w$ and $T_{R}$ had negative and high weights with the first component, with values of $-0.83,-0.88$ and -0.68 , respectively. Furthermore, the variables $T_{E X P}, R_{R}$ and $P_{E X P}$ had positive and low weights of $0.09,0.19$ and 0.23 , respectively. Consequently, the variables $V_{E}, w$ and $T_{R}$ can be interpreted to determine the one that contributed more to separate these two groups, whereas $T_{E X P}, R_{R}$ and $P_{E X P}$ contributed less. This exploratory analysis revealed that $V_{E}$ and $T_{R}$ depend strongly on sex, whereas $T_{\text {EXP }}, R_{R}$ and $P_{\text {EXP }}$ depend weakly on sex. These results, combined with those presented in Fig. 7, show that the $V_{E}$ in males was greater than in females by approximately $25-$ $30 \%$, whereas $R_{R}$ was only $5 \%$.

\section{Conclusions}

(1) A methodology was developed to determine highly reactive animals and to select animals for use in indirect calorimetry experiments with a facial mask.

(2) The respiratory rate was an efficient indicator to select animals for the examination of indirect calorimetry experiments with a facial mask.

(3) The skin, hair-coat surface and expired air temperatures depend on the air temperature, whereas the rectal temperature depends on the time of day.

(4) Metabolic heat production, ventilation and the respiration rate remained generally stable, regardless of the variation in air temperature from 25 to $34^{\circ} \mathrm{C}$.

(5) The ventilation rate and rectal temperatures were the physiological variables that showed the greatest difference between the sexes. 


\section{Acknowledgments}

The present study was supported by a grant from Coordenação de Aperfeiçoamento de Nível Pessoal Superior (CAPES) and from the São Paulo Research Foundation (FAPESP) process number 14/ 09639-7.

\section{References}

Brito, L.F.C., Silva, A.E.D.F., Unanian, M.M., Dode, M.A.N., Barbosa, R.T., Kastelic, J.P., 2004. Sexual development in early- and late-maturing Bos indicus and Bos indicus $\times$ Bos taurus crossbred bulls in Brazil. Theriogenology 62, 1198-1217.

Brown-Brandl, T.M., Nienaber, J.A., Eigenberg, R.A., Hahn, G.L., Freetly, H.C., 2003. Thermoregulatory responses of feeder cattle. J. Therm. Biol. 28, 149-157.

Brown-Brandl, T.M., Nienaber, J.A., Eigenberg, R.A., Mader, T.L., Morrow, J.L., Dailey, J.W., 2006. Comparison of heat tolerance of feedlot heifers of different breeds Livest. Sci. 105, 19-26.

Brouwer, E., 1965. Blaxter, K.L. (Ed.), Energy Metabolism. Academic Press, London, p. 441.

Brosh, A., Aharoni, Y., Degen, A.A., Wright, D., Young, B.A., 1998. Effects of solar radiation, dietary energy, and time of feeding on thermoregulatory responses and energy balance in cattle in a hot environment. J. Anim. Sci. 76, 2671-2677.

Costa, C.C.M., 2013. Efeito da Radiação Solar e Temperatura na Emissão de Metano Associado à Produção e Perda de Calor em Bovinos (Ph.D. Diss). Programa de Pós-Graduação em Zootecnia, Faculdade DE Ciências Agrárias e Veterinárias, Universidade Estadual Paulista "Júlio DE Mesquita Filho", Jaboticabal.

da Silva, R.G., Maia, A.S.C., 2013. Principles of Animal Biometeorology, first ed. Springer, New York.

Eigenberg, R.A., Brown-Brandl, T.M., Nienaber, J.A., Hahn, G.L., 2005. Dynamic response indicators of heat stress in shaded and non-shaded feedlot cattle: Part 2 Predictive relationships. Biosyst. Eng. 91, 111-118.

Finch, V.A., 1985. Comparison of non-evaporative heat transfer in different cattle breeds. Aust. J. Agric. Res. 36, 497-508.

Gebremedhin, K.G., Lee, C.N., Hillman, P.E., Collier, R.J., 2010. Physiological responses of dairy cows during extended solar exposure. Trans. ASABE 53, 239-247.

Johnson, D.E., 1998. Principal components analysis. In: Applied multivariate methods of data analyses. Duxbury Press, London, pp. 93-146.

Littell, R.C., Milliken, G.A., Stroup, W.W., Wolfinger, R.D., Schabenberger, O., 2006. SAS for Mixed Models, Second ed. SAS Institute Inc, Cary, NC.

Maia, A.S.C., Silva, R.G., Loureiro, C.M.B., 2005. Respiratory heat loss of Holstein cows in a tropical environment. Int. J. Biometeorol. 49, 332-336.

Maia, A.S.C., Gebremedhin, K.G., Nascimento, S.T., Carvalho, M.D., Simão, B.R., Camerro, L.Z., Chiquitelli Neto, M., 2014. Development of Facial Masks for Indirect Calorimetric Studies for Livestock. In: ASABE and CSBE/SCGAB Annual International Meeting Sponsored by ASABE - Montreal, Quebec, Canada.

Maia, A.S.C., Nascimento, S.T., Nascimento, C.C.N., Gebremedhin, K.G., 2016. Thermal equilibrium of goats. J. Therm. Biol. 58, 43-49. http://dx.doi.org/10.1016/j. jtherbio.2016.03.012.

Mainly, B.F.J., 1994. Principal components analysis. In: Multivariate statistical methods, 2nd ed. Chapman \& Hall, London, pp.76-92.

McArthur, A.J., 1987. Thermal interaction between animal and microclimate a comprehensive model. J. Theor. Biol. 126, 203-238.

McDowell, R.E., Lee, D.H.K., Fohrman, M.H., Anderson, R.S., 1953. Respiratory activity as an index of heat tolerance in Jersey and Sindhi $\times$ Jersey (F1) crossbred cows. J. Anim. J. Anim. Sci. 12, 573-581.

McLean, J.A., Stombough, D.P., Downie, A.J., 1983. Body heat storage in steers (Bos taurus) in fluating thermal environments. J. Agric. Sci. 100, 315-322.

McLean, J.A., 1963. The partition of insensible losses of body weight in heat from cattle under various climatic conditions. J. Physiol. 167, 427-447.

McLean, J.A., 1972. On the calculation of heat production from open-circuit calorimetric measurements. Br. J. Nutr. 27, 597-600.

Piccione, G., Coala, G., Mortola, J.P., 2005. Scaling the daily oscillations of breathing frequency and skin temperature in mammals. Comp. Biochem. Physiol. 140, $477-486$.

Robertshaw, D., 2006. Mechanisms for the control of respiratory evaporative heat loss in panting animals. J. Appl. Physiol. 101, 664-668. http://dx.doi.org/ 10.1152/japplphysiol.01380.2005.

SAS Institute Inc, 1995. Logistic Regression Examples Using the SAS System. SAS Institute Inc, Cary, NC.

Schmidt-Nielsen, K., 2013. Animal Physiology: Adaptation and Environment, fifth ed. Cambridge Univ. Press, Cambridge.

STATSOFT, INC., 2007. Statistica (data analysis software system), version 7.

USDA, 2014. USDA Foreign Agricultural Service. (Available at: 〈http://apps.fas.usda. gov/psdonline/ $\rangle$. Accessed 08 September 2015.

West, J.W., 1994. Interactions of energy and bovine somatotropin with heat stress. J. Dairy Sci. 77, 2091-2102.

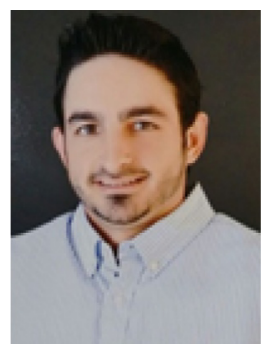

Leandro Zuccherato Camerro is a MSc degree candidate in the Graduate Program in Animal Science, São Paulo State University (UNESP/FCAV), Jaboticabal, São Paulo, Brazil, under the supervision of Professor Alex Sandro Campos Maia. His thesis focuses on the thermoregulation of beef cattle bred in tropical environments.

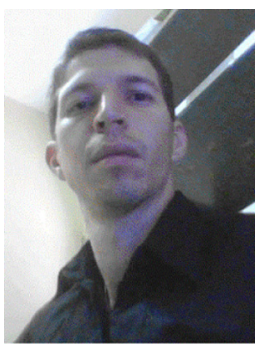

Alex Sandro Campos Maia received his undergraduate degree in agronomy engineering in 2000 from the Federal University of Acre (UFAC). He received his doctorate in Animal Science from São Paulo State University (UNESP) where he currently teaches animal biometeorology. His interests include the development of thermal propagation models, thermal balance, and thermal regulation applied to animal production.

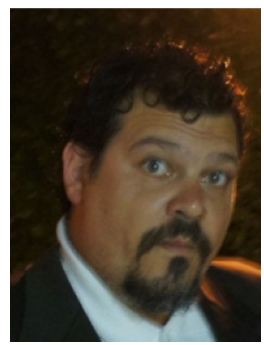

Marcos Chiquitelli Neto is an Assistant Professor at São Paulo State University (UNESP/FEIS), Ilha Solteira, São Paulo, Brazil. He has extensive experience in studies with cattle bred in tropical environments with a focus on animal welfare and thermoregulation.

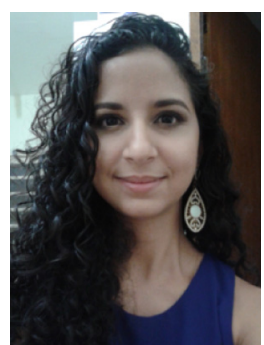

Cíntia Carol de Melo Costa is a Ph.D. candidate in the Graduate Program of Animal Science at Sao Paulo State University (UNESP), Jaboticabal, São Paulo, Brazil. Her master's thesis focused on the thermoregulation of beef cattle in tropical environments, which is also the topic of her doctoral work.

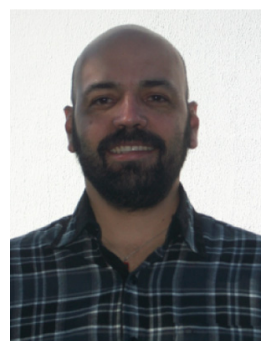

Patric André Castro has an undergraduate degree in Animal Science with an emphasis on sustainable animal production from the State University of Santa Catarina (UDESC). He has a background in bioclimatology, ethology, and animal welfare. He is currently a member of the Group of Ambience and Animal Welfare (GABA) and a former member of the PETZOO Group (Tutorial Education Program). 